\title{
Alpha Prototype Fabrication of Manual Cum Automatic Seed Sowing Machine
}

\author{
Rajesh Ramadass ${ }^{1}$, Anantha Bharathi ${ }^{2}$, Sridhar $\mathrm{S}^{3}$ and Tharanraj $\mathrm{N}^{4}$ \\ \{rrh.prod@psgtech.ac.in, \\ ananthabharathi462@gmail.com ${ }^{2}$,sridharcool3030@gmail.com ${ }^{3}$, cracytharan93@gmail.com ${ }^{4}$ \}
}

\author{
${ }^{1}$ Assistant Professor, Product Design and Development Laboratory, PSG College of \\ Technology, Coimbatore 641004 INDIA, ${ }^{2,3,4}$ BE Production Engineering Students, PSG \\ College of Technology, Coimbatore 641004 INDIA
}

\begin{abstract}
Automatic seed sowing machine are expensive and not affordable by small farmers in India. Traditional method of seed sowing practice causes muscular fatigue. It also leads to severe back ache. This paper focuses on the prototype development of manual cum automatic seed sowing machine at a minimum cost and to reduce the muscular fatigue associated with traditional method of seed sowing practice. The activities of this work include ideation, detail design, analysis and finally prototype development. In the ideation stage, solutions were sketched and finally best solution was selected using weighted matrix method. The detail design emphasis on the overall dimension and bill of materials for the proposed final model. The ergonomic analysis was performed in Catia V5 using Manikin and results indicated moderate risk. The cost estimation of the final product was presented. A minor variation of the developed prototype is recommended for commercialization.
\end{abstract}

Keywords: Ideation, Detail design, Analysis, Manual cum automatic seed sowing machine.

\section{Introduction}

Agriculture is one of the predominant occupation of people in India. It is identified that India stands second in production of fruits and vegetables next to China. World's $17 \%$ percentage total population depends on the $2.3 \%$ of world's topographical part and $4.2 \%$ of aquatic resources in world [1]. The prediction of food requirement in India with the present production and consumption rate indicated total food grain requirement to be 240 Metric ton by 2020 and 300 Metric ton by 2025 [2]. In the present situation, the scientific management of natural resources is very important for the sustainable agricultural farming and to minimize the yield losses, maximize the superiority of Agro production. The natural resources effective utilization is essential to increase the input proficiency and land productivity. It is also important to maximize the labor productivity by reducing labor cost and minimizing drudgery devices though it is found to be cost effective and eco-friendly. The United Nations Asian and Pacific centre for Agricultural Engineering and Machinery (UNAPCAEM) report indicated that the level of mechanization by sowing is bare minimum [3]. The survey has been 
conducted for the availability of mechanization in the farmers and results are indicated in the Figure 1.

The present status of farm mechanization during sowing and planting was observed and shown in Table 1. This article explains the development of Alpha prototype for improving the agricultural seed sowing process in the ploughed land. A vehicle with four wheels operated by a DC motor was developed. The proposed system in this work is intended to cultivate the farms in a particular array of patterns which are at a fixed distance depending on the crop.

Table 1: Present status of mechanization

\begin{tabular}{|c|l|}
\hline Technology & Present status \\
\hline Drilling & $\begin{array}{l}\text { Ploughing using animals, Seed } \\
\text { drillers operated by tractor and } \\
\text { power tiller, fertilizer and seed } \\
\text { driller. }\end{array}$ \\
\hline Planting & $\begin{array}{l}\text { Dibbler, planting with inclined } \\
\text { plate planter and planting using } \\
\text { pneumatic plate planter }\end{array}$ \\
\hline $\begin{array}{l}\text { Tubers and } \\
\text { rhizomes } \\
\text { planting }\end{array}$ & $\begin{array}{l}\text { Animal Potato planters, planting } \\
\text { using tractor and power tiller. }\end{array}$ \\
\hline
\end{tabular}

\section{Factots Influencing Seed Sprouting}

The mechanical factors that influence seed sowing and sprouting are listed as follows.

- The uniform depth related to the placement of seeds

- The transverse displacement with respect to row.

- The covering method of soil over seed.

- The mixing level of fertilizer and seed positioning in the grooves created in the farm land.

The points mentioned above are important and the need of optimizing the above factors should be done in an economical way. In addition to the above mechanical factors, there are the physical factors which contributes to the germination of seeds such as the size of seed, the distance between plants and planting depth [4]. The effects are analyzed with the different types of seed size and charted and also the distance of plants and planting depth are discussed.

\section{Methodology}

An established procedure for the development of product is followed to solve the problem and to transform the concept generated during ideation phase into final product [5]. A design activity consists of supporting the marketing and business case vision of product development. The different procedures used in the product design and development process also their merits and demerits are reviewed by researchers. The technical activities that are planned in a sequential order for the development of prototype. 
The flow chart represents the procedure followed in this work for prototype development of manual cum automatic seed sowing machine. Initially the Customer requirements were identified through the Voice of Customer (VOC) techniques. Based on their problems, the concept design was sketched by hands and the weighted matrix technique was used to identify the best concept in the ideation phase. Then the detailed design was obtained for manufacture of prototype. Analysis was planned to validate the proposed design and to minimize the risk while usage. Finally, alpha prototype was developed and cost estimation was proposed.

\section{Ideation}

Ideation is the effective usage of brain creativity for generating solutions for the problem concerned in this work. The initial ideas were developed with brainstorming technique. The project team discussed about the problem with a group of ten framers in the Andipatty locality of Salem district. The solution pointed out are

- Efficient use of renewable energy

- Easy maintenance and safety

- $\quad$ Easy handling

- Low cost automation for sowing

\section{- SKETCHING}

The sketching practice consists of drawing the solutions in a paper using hand and a pencil. The CAD practice is not economical and needs computer integrated tools for creating the solutions. The concepts are roughly described initially by free hand sketches. Further, appropriate pencils are used for improving the finish in the ideation stage whereas CAD software is applied for the detail design such as part modeling, assembly and drafting. The manual sketching is considered as an advantageous practice as it offers better flexibility of speed in the ideation phase. Freehand sketching is reported as one of the popular methods to solve a particular problem and to represent the solution for the product [5]. Free hand sketching is a visualization and creative technique practiced effectively designers across the world to solve problems in product. This method offers better flexibility and supports successive iteration of the concepts as it is not restricted by geometrical and topological constraints.

Sketch 1 shows the chain and sprocket mechanism used in the seed sowing practice and plough fixed at the front end of the design.

Sketch 2 indicates a structural frame attached to the front wheel which shows the mechanism for seed sowing practice. Plough and seed feeding tank attached to the back wheel. 


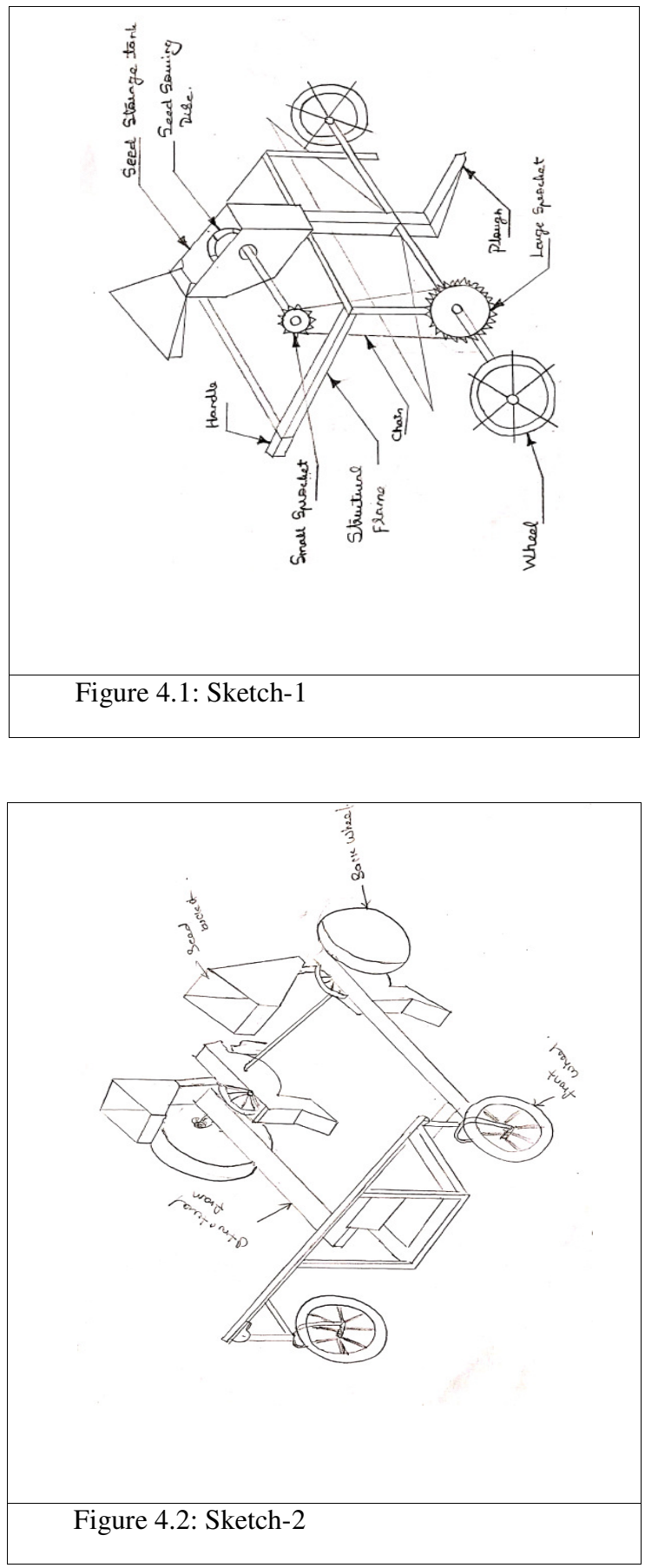




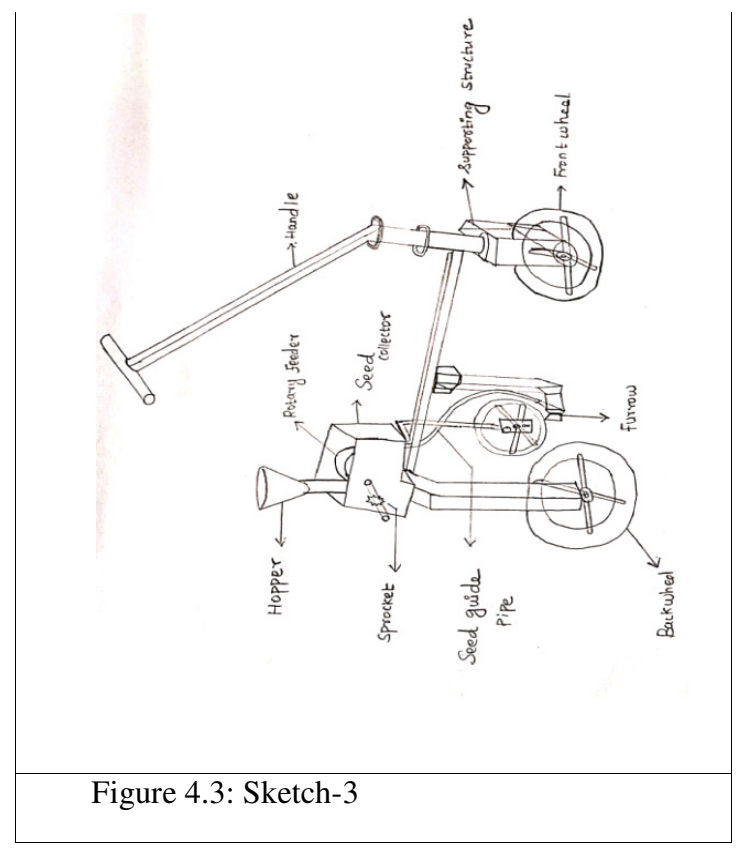

Fig 4.1,4.2,4.3,4.4 \& 4.5 shows the solutions obtained with the objective of affordable seed sowing machine for the farmer community. The important components such as seed storage tank, wheels, mechanism for sowing the seed are indicated in the concepts generated. 


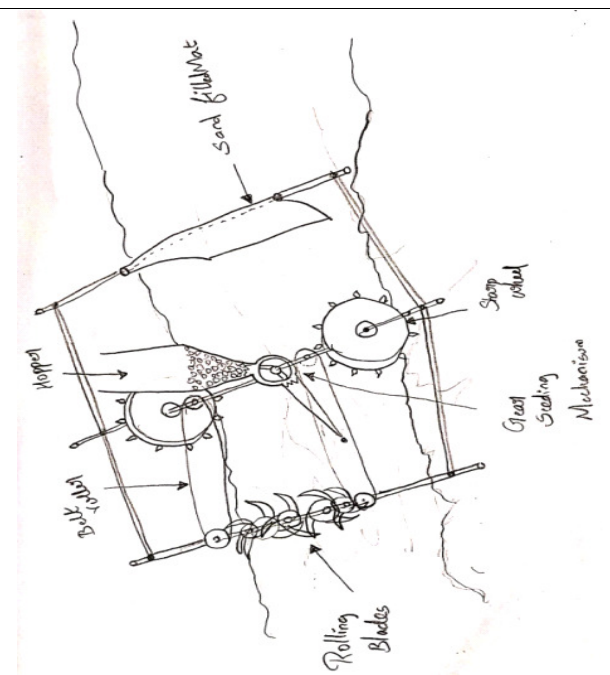

Figure 4.4: Sketch-4

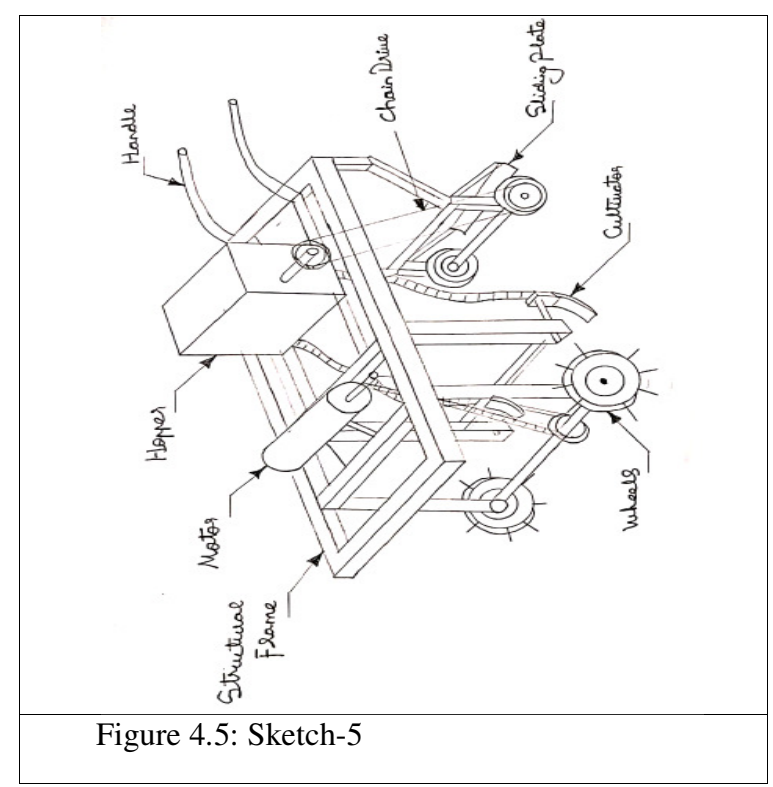

Sketch 3 employs a typical three-wheel kid cycle structure and a grip handle for seed sowing practice. Plough fixed in the centre frame between front and back wheel. Seed storage tank present at the rear end of the design. 
Sketch 4 incorporates the belt and pulley mechanism for the seed sowing practice. Roller blades are used in this design for ploughing. Hooper and spur gear arrangement proposed in the centre of the design.

Sketch 5 includes a trolley structure with a motorized unit with a chain drive for automatic operation and additional chain drive coupled with hooper for manual operation of seed sowing machine.

\section{Concept Evaluation and Selection}

In the development of products, it is observed that as the concepts are sketched, the created sketches are compared and rated for the selection of best concept among the concept sketches developed.

The weighted matrix method was used to compare and quantify the concepts generated [6]. The concepts emerged in the previous phase is mentioned in the rows of the weighted matrix. The design criteria for the development of seed sowing machine are listed along the columns of the matrix. In this stage, the team has assigned the weightage based on the relative importance of the selection criteria and evaluated the criterion against the concepts by using a scale of (1-10) which is shown in the Table 2 . The evaluated value and weightage are multiplied to obtain the individual score for each concept mapped against a particular criterion. The average score of each concept is summarized in each row based on which the concepts are compared and best conceptual design was identified was identified as concept 5 . The selected concept has better ease of handling, reduces muscular fatigue and allpurpose seeds could be used while comparing with the other concepts obtained as solution for the problem concerned in this work.

\begin{tabular}{|c|c|c|c|c|c|c|c|c|c|}
\hline${ }_{4}^{\text {Design criteria }}$ & $\begin{array}{l}\mathbf{D} \\
0 \\
0 \\
0 \\
0 \\
0 \\
\mathbf{0} \\
0 \\
0 \\
0 \\
0 \\
0\end{array}$ & 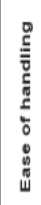 & $\begin{array}{l}8 \\
\vdots \\
5 \\
\frac{\pi}{5} \\
0 \\
5 \\
\frac{5}{\pi} \\
\Sigma \\
\Sigma\end{array}$ & 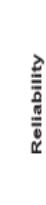 & 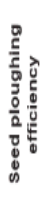 & 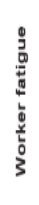 & 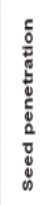 & 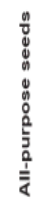 & $\underset{్}{\xi}$ \\
\hline & 0.08 & 0.12 & 0.10 & 0.10 & 0.18 & 0.20 & 0.03 & 0.04 & 1.0 \\
\hline Concept 1 & & & & & & & & & 6.67 \\
\hline Concept 2 & & & & & & & & & 6.11 \\
\hline Concept 3 & & & & & & & & & 5.36 \\
\hline Concept 4 & & & & & & & & & 5.79 \\
\hline Concept 5 & & & & & & & & & 7.03 \\
\hline
\end{tabular}

Table 2: Weighted matrix for concept selection 


\section{Embodiment Design}

Embodiment stage is concerned about dimensions, geometry and materials in the product. The word embody represents "to represent an idea". The important work is carried out in the Embodiment design. The overall dimensions, geometry and materials used in this work is finalized based on the best-in-class products in the market used for seed sowing practice. The CAD model is developed based on the input obtained from the embodiment stage.

\section{- CAD Modeling and Detail Design}

The CAD modeling was done using PTC CREO where detail design with the bill of material is developed for production purpose. The three-dimensional CAD model of the proposed design is shown in the Figure 6.1. It contains the various parts like frame, front /rear wheel, shaft, motor, hopper, chain drive, handle bar and cultivator. Fully assembled view of the manual cum automatic seed sowing machine

\section{Rula Analysis Using Catia}

Rapid Upper Limb Assessment (RULA) is intended to measure the ergonomic risk parameters related to the individual workers in the work environment. This ergonomic assessment tool includes the bio mechanical and postural load necessities of job tasks, requirements on the neck, trunk and upper extremities. A worksheet of single page is used to evaluate the required body posture, force and repetition. As per the evaluation, score is obtained for specific portion in the body and represented in section A for the arm and wrist, and section B for the neck and trunk. The data for specific portion is obtained and then the tables on the form is used to organize the risk factor parameters, a single score generated indicates the level of risk.

RULA has user friendly environment for performing the assessment using Manikin. In the RULA worksheet, the evaluator will obtain a score for the specific body portion: upper arm, lower arm, wrist, neck, trunk and legs. The information for the specific region is collected and score indicates the level of Musculoskeletal Disorders (MSD) risk as shown in below in Figure 7.1.

\begin{tabular}{|c|l|}
\hline Score & Level of MSD Risk \\
\hline $1-2$ & negligible risk, no action required \\
\hline $3-4$ & low risk, change may be needed \\
\hline $5-6$ & medium risk, further investigation, change soon \\
\hline $6+$ & very high risk, implement change now \\
\hline
\end{tabular}




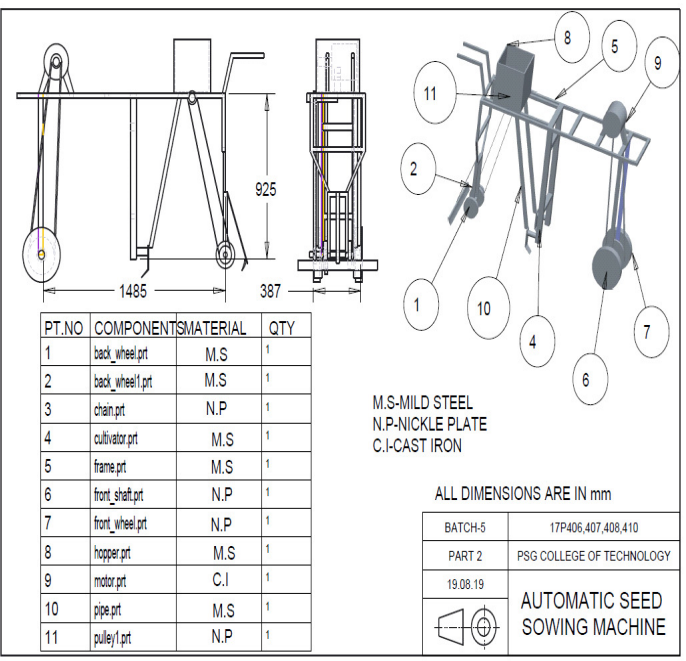

Figure 7.1: Level of MSD risk Right Hand

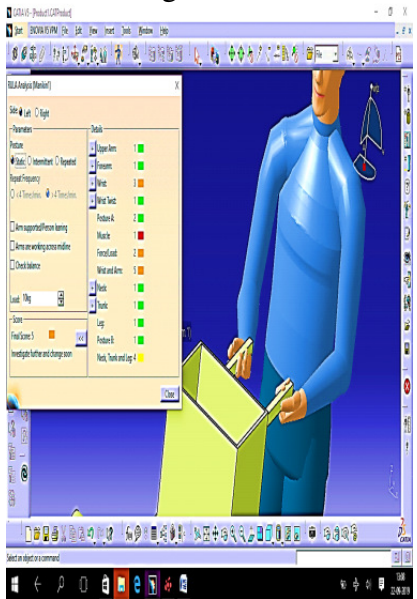

a $<\rho 0$ 月日eng

Figure 7.2 Static posture 


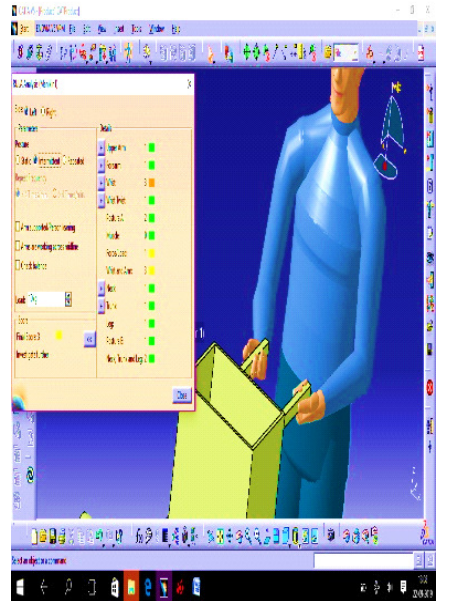

Figure 7.3 Intermittent posture

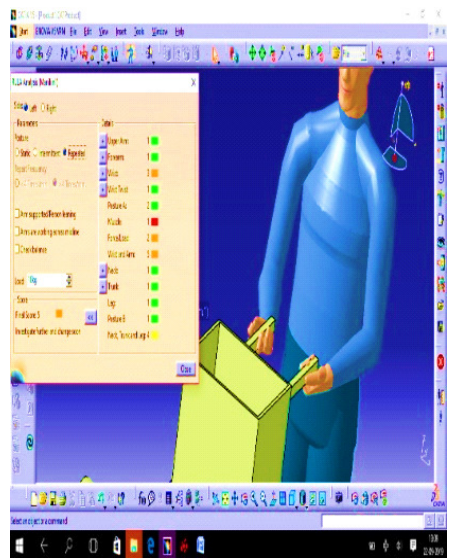

Figure 7.4 Repeated posture

Left Hand 


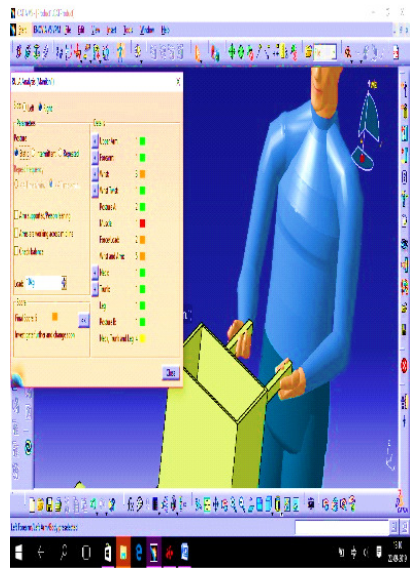

Figure 7.5 Static posture

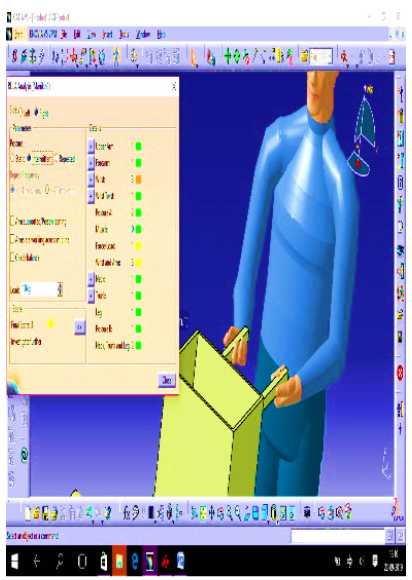

Figure 7.6 Intermittent posture 


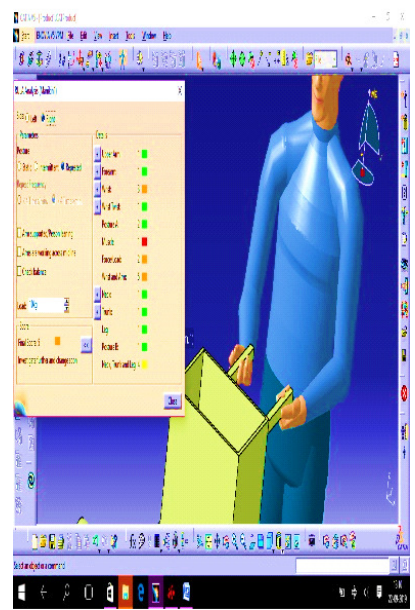

Figure 7.7 Repeated posture

Figure7.2-7.7 indicates the right hand and left-hand ergonomic posture analysis performed using Catia V5. indicated risk assessment at various body regions at upper arm, lower arm, wrist, neck, trunk and legs and was found that level of MSD risk was less than 5

\section{FE Analysis}

Finite Element Method is used in this work to obtain the total deformation of the plough in the seed sowing machine. The deformation location in the cultivator is determined by FEA. The plougher of best conceptual design identified in the ideation phase is subjected to FE analysis in the CAD/CAE environment.

\section{- Total Deformation}

\section{Load: $6000 \mathrm{~N}$}

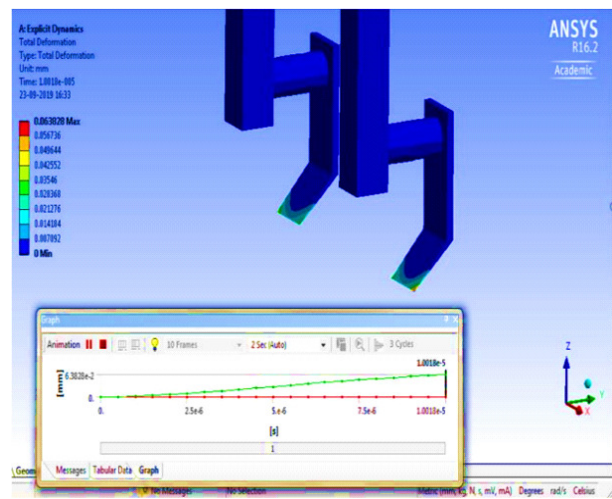

Figure 8.1: Total deformation

Figure 8.1, at cultivator cross section, illustrates the total deformation of maximum $0.063 \mathrm{~mm}$ which indicates the deformation is very minimum. 


\section{- Equivalent stress}

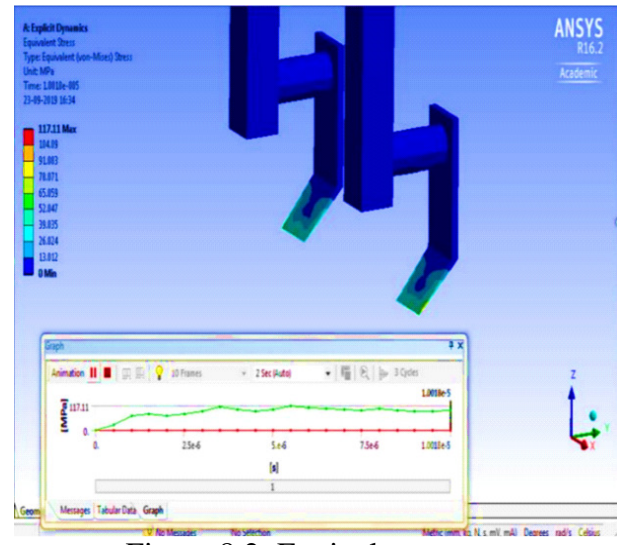

Figure 8.2: Equivalent stress

Figure 8.2, at cultivator cross section, illustrates explicit dynamics with respect to time is $0.0001 \mathrm{sec}$ and (equivalent $\max 117.11 \mathrm{MPa}$ ).

\section{Alpha Prototype of Seed Sowing Machine}

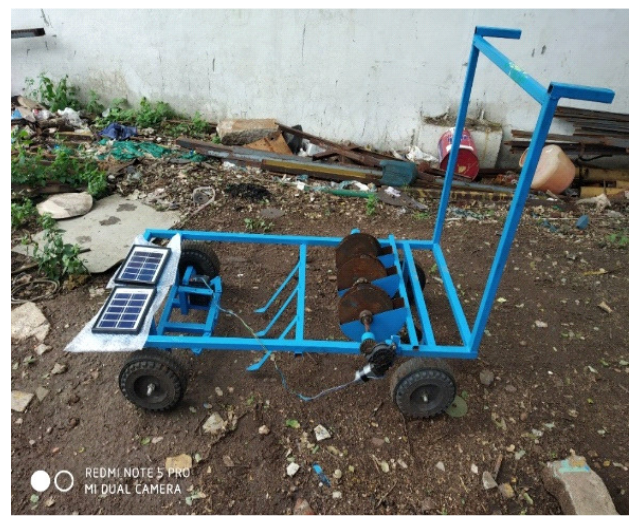

Figure 9.1: Alpha prototype of product

The optimum materials from the material library were considered for construction of chassis. The material chosen for the chassis fabrication should have light weight characteristics and should not be too heavy for framers. However, aluminum material channels consist of application of aluminum which is costlier and thus the alternate option found is Steel. Steel pipe is much economical and also possess required strength and good weldability. Therefore, the steel is the material used in the fabrication of chassis structure for alpha prototype of manual cum automatic seed sowing machine. The fabricated alpha prototype is shown in the Figure 9.1. After the chassis fabrication was completed the motors were mounted 
on the chassis for testing. Front and rear wheel was fixed at the both ends of the shaft. The cost estimation of alpha protype has been shown in Table 3.

\section{References}

[1] Agricultural Engineering Data Book 2008,Central Institute of agricultural Engineering, Bhopal.

[2] Data Book 2007, Indian Agricultural Statistics Research Institute, New Delhi.

[3] Proceedings of 20th National Convention of Agricultural Engineers and national Seminar on Farm Mechanization for Diversification of Agriculture. Jan. 19-20, 2007. Dept. of Farm Power and Machinery, PAU, Ludhiana,

[4] Swetha S.1 and Shreeharsha G.H.2,"Solar Operated Automatic Seed Sowing Machine", Cloud Publications International Journal of Advanced Agricultural Sciences and Technology 2015, Volume 4, Issue 1, pp. 67-71, Article ID Sci-223, ISSN: 2320 - 026X, 26 February 2015.

[5] Kevin Otto and Kristin wood 2006 , Product design-Techniques in reverse engineering and new product development, Pearson Education, India.

[6] Karl T.Ulrich and Steven D.Eppinger 2004, Third Edition, Tata McGraw-Hill Publishing Company Limited.

[7] M.Priyadarshini, Mrs.L.Sheela "Command Based Self Guided Digging and Seed Sowing Rover" International Conference on Engineering Trends and Science \& Humanities, ISSN: 2348 8379, ICETSH-2015.

[8] Wells R, Moore A, Potvin J, Norman R (1994) Assessment of risk factors of work related musculoskeletal disorders. Appl Ergon 25(3):157-164 